\title{
Is duodenal biopsy appropriate in areas endemic for Helicobacter pylori?
}

\author{
Abdurrahman Sahin, ${ }^{1}$ Gulcin Cihangiroglu, ${ }^{2}$ Yilmaz Bilgic, ${ }^{1}$ Turan Calhan ${ }^{3}$, Mustafa Cengiz ${ }^{4}$ \\ ${ }^{1}$ Department of Gastroenterology, Elazig Training and Research Hospital, Elazig, Turkey \\ 2Department of Pathology, Elazig Training and Research Hospital, Elazig, Turkey \\ ${ }^{3}$ Department of Gastroenterology, Private Turkey Hospital, Istanbul, Turkey \\ ${ }^{4}$ Department of Gastroenterology, Dr. Abdurrahman Yurtaslan Ankara Oncology Training and Research Hospital, Ankara, Turkey
}

\begin{abstract}
OBJECTIVE: The primary reason for obtaining duodenal biopsy sample is to diagnose celiac disease. Helicobacter pylori (H. pylori) and drug injury are common causes of duodenitis. The aim of this retrospective study was to explore effects of $H$. pylori and drugs on duodenal mucosa.
\end{abstract}

METHODS: Duodenal biopsy samples of patients who underwent upper gastrointestinal endoscopy (UGIE) between February 2014 and December 2014 were retrospectively examined. Clinical symptoms, referral indications, endoscopic findings, $H$. pylori status, and drug history were recorded. Duodenal biopsy findings were compared based on presence of $H$. pylori and drug history.

RESULTS: Of 2389 patients who underwent UGIE, 206 had duodenal biopsy. Eight patients (3.9\%) were diagnosed with celiac disease. After excluding cases with celiac disease, 76 patients of remaining 198 patients (36.9\%) had duodenal histopathological abnormality. H. pylori was found in 95 (47.9\%) patients. Drug usage was less common (42\%). Of patients who had histopathological duodenitis, 59\% were $\mathrm{H}$. pylori-infected. Rate of duodenitis was higher in $\mathrm{H}$. pylori (+) group than in H. pylori (-) group ( $45 \%$ vs $27.1 \%$; odds ratio, 2.4 ; $95 \%$ confidence interval, $1.3-4.4$; $\mathrm{p}=0.005)$. There was no difference between groups regarding drug use in terms of histopathological duodenitis.

CONCLUSION: H. pylori is the major contributor to duodenitis in high prevalence regions. Serological testing may be more appropriate before performing duodenal biopsy in patients with suspected celiac disease.

Keywords: Acetylsalicylic acid; celiac disease; duodenitis; Helicobacter pylori; nonsteroidal anti-inflammatory drugs.

$\mathrm{U}$ pper gastrointestinal endoscopy (UGIE) is a common procedure to investigate dyspepsia, dysphagia, and other upper gastrointestinal (GI) symptoms [1]. Inspection of duodenum is one of the basic components of routine upper GI endoscopic examination. Duodenal endoscopic findings give important clues for a wide range of disorders affecting upper GI tract.

Duodenal biopsy sample is commonly obtained to investigate iron deficiency anemia, malabsorption, neoplasia, and infectious enteritis. However, various other disorders, such as infectious disease, inflam-

Received: February 19, 2017 Accepted: April 05, 2017 Online: May 10, 2017

Correspondence: Dr. Abdurrahman SAHIN. Elazig Egitim ve Arastirma Hastanesi, Gastroenteroloji Klinigi, Elazig, Turkey. Tel: +90 424 - 2122717 e-mail: arahmansmd@yahoo.com 
TABLE1. Grading criteria of duodenal biopsies according to definitions of

Serra et al. [5]

Definition Criteria

Number and site of biopsy specimens

Villous height and architecture

Ratio normal villous to crypt (V:C)

Surface enterocytes

Brush borders

Presence of crypt hyperplasia

Intraepithelial lymphocyte count

(per 100 epithelial cells)

Gastric metaplasia in chronic duodenitis

Presence of microorganisms

Neoplasia
Normal, broad, or blunted

Range from 3:1 to $5: 1$

Normal, flattened, or damaged

Preserved or lost

Present/Absent

Range from $1: 5$ to $5: 5$

Normal (1:5) / Increased (range from 2:5 to 5:5)

Present/Absent

Giardia, Cryptosporidium, Microsporidia, Isospora belli, Cyclospora, Mycobacterium avium-intracellulare, Cytomegalovirus, Cryptococcus neoformans

Presence of benign or malignant tumor

(adenoma or carcinoma, carcinoid, lymphoma) matory disorder, toxic or physical reactions, may cause duodenal mucosal injury and result in appearance of duodenitis on endoscopic examination [2].

Determination of the cause of duodenitis is important, but histopathological findings do not always correlate with endoscopic findings. It is

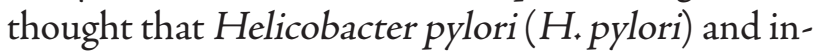
jury due to use of pharmaceutical drugs, including nonsteroidal anti-inflammatory drugs (NSAIDs), acetylsalicylic acid (ASA) and other antiplatelet drugs, are common cause of duodenitis [3,4].

The aim of this retrospective study was to evaluate duodenal biopsy samples taken from patients who underwent endoscopic examination. Correlation of histopathological findings with $H_{\text {. pylori }}$ and drug toxicity was also assessed.

\section{MATERIALS AND METHODS}

\section{Patient data}

This retrospective study was carried out using data of consecutive patients who underwent endoscopic examination for several indications, including dyspepsia, anemia, chronic diarrhea, epigastric pain, and reflux symptoms, in the gastroenterology department of Elazig Training and Research Hospital (Turkey). Endoscopy records from February 2014 through December 2014 were examined for patients who had duodenal biopsy performed. Endoscopic duodenitis was detected according to presence of erythema, edema, or erosion. Endoscopic findings compatible with celiac disease, such as nodularity, mosaic pattern, and scalloping, were also recorded as endoscopic duodenitis. Demographic and medical data of patients were obtained from hospital databases. Drug prescription data for evaluation of patients in terms of drug usage, especially NSAIDs, ASA, or other antiplatelet drugs, were also obtained from hospital records. In patients who were diagnosed as celiac disease, serological markers, including $\mathrm{IgA}$ and $\mathrm{IgG}$ antibodies against tissue transglutaminase ( $\mathrm{tTG}$ ), endomysial antibodies (EMA), and gliadin antibodies (AGA), were also recorded. Patients who had inadequate demographic or clinical data or inadequate drug history were excluded.

\section{Histopathological assessment}

Duodenal biopsy samples were assessed by one expert pathologist (GC) who was blinded to endoscopic findings. Histopathological findings were evaluated according to definition and classification of duodenal biopsy findings by Serra et al, to ensure objective criteria (Table 1) [5]. Diagnosis of H. pylori infection was based on results of rapid urease 


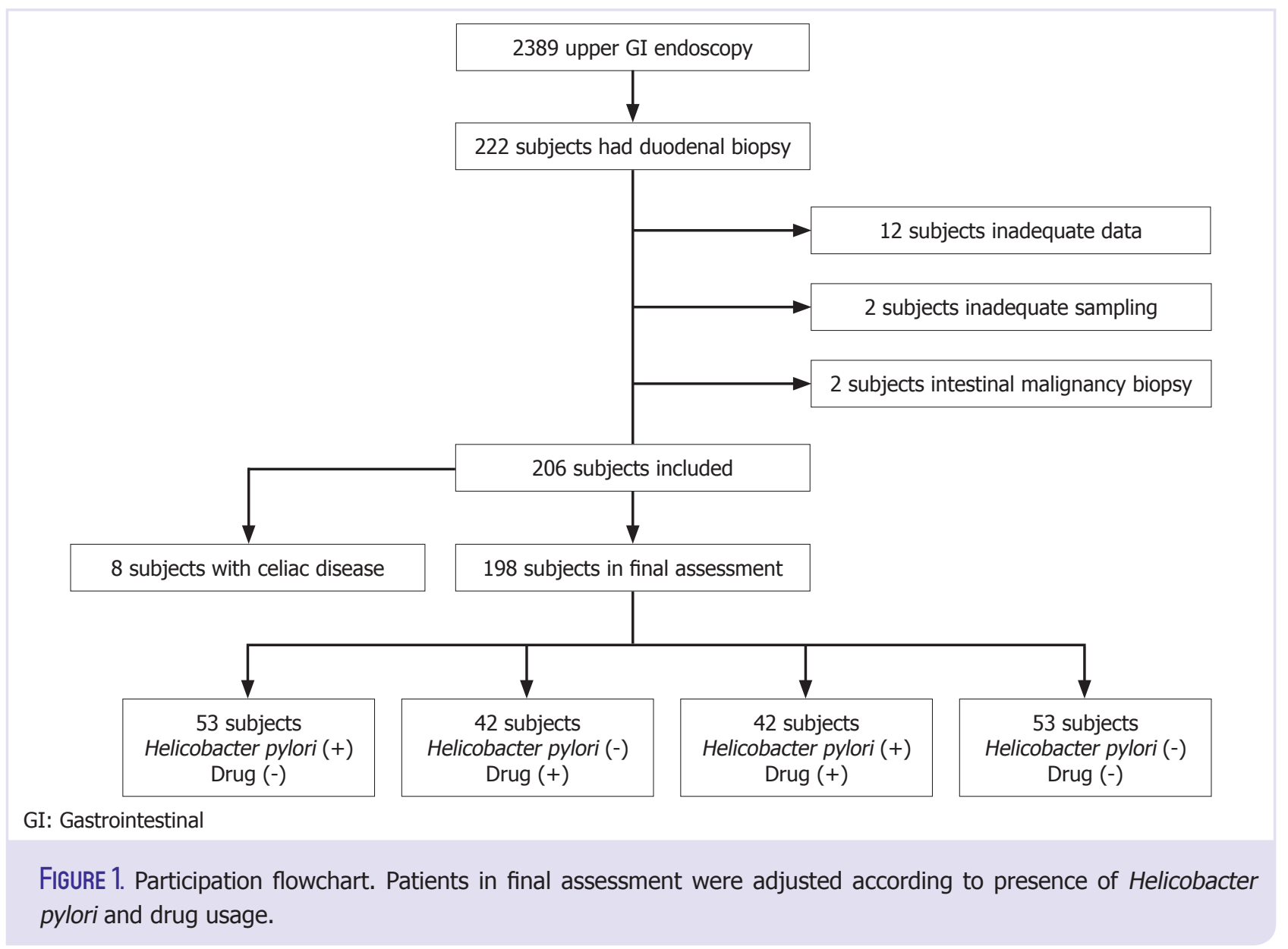

test or positive identification of the bacteria either on routine stains (Wright-Giemsa stain) or immunostain of gastric biopsies. Histological changes in patients diagnosed with celiac disease were classified according to Marsh classification [6]. Patients who had inadequate duodenal sampling were excluded. Patients diagnosed as malignancy with histopathological assessment of duodenal biopsy samples were also excluded.

\section{Statistical analysis}

Statistical analysis was performed using IBM SPSS Statistics for Windows, Version 21.0. (IBM Corp., Armonk, NY, USA) software. Quantitative data were expressed as mean $\pm \mathrm{SD}$, while nominal data were expressed as number (percent). Chi-square test and simple odds ratio (OR) (95\% confidence interval $[\mathrm{CI}])$ were performed. $\mathrm{P}$ value $<0.05$ was considered significant.

\section{RESULTS}

Total of 2389 upper GI endoscopy reports were screened. Among those, 222 patients (9.3\%) had duodenal biopsy sampling performed. Clinical data of 12 patients were inadequate and those patients were excluded. Two patients were excluded because samples were either inadequately oriented or were distorted during processing. Two cases were diagnosed as intestinal malignancy ( 1 carcinoid tumor, 1 ampullary carcinoma). In all, 206 duodenal biopsy samples were accepted for final analysis (Figure 1).

Duodenitis was found in 170 patients (82.5\%) as endoscopic finding. Duodenal biopsy sample was taken from remaining 36 patients $(17.5 \%)$ to investigate anemia (iron deficiency and/or vitamin B12 deficiency) in 26 (12.6\%) and/or chronic diarrhea in 11 (5.3\%), and intestinal lymphangiectasia in 8 patients. Demographic and clinical features, referral 
TABLE2. Demographic characteristics, UGIE indications and endoscopic findings of the study population

\begin{tabular}{|c|c|c|}
\hline & \multicolumn{2}{|c|}{ Total $(n=206)$} \\
\hline & $\mathrm{n}$ & $\%$ \\
\hline Age, years (mean $\pm S D)$ & \multicolumn{2}{|c|}{$44.7 \pm 17.5$} \\
\hline Gender, female & 126 & 61.2 \\
\hline Helicobacter pylori presence & 100 & 48.5 \\
\hline Drugs $^{\ddagger}$ & 88 & 42.7 \\
\hline \multicolumn{3}{|l|}{ Referral indication } \\
\hline Epigastric pain & 90 & 43.7 \\
\hline Dyspepsia & 29 & 14.1 \\
\hline Regurgitation & 10 & 4.9 \\
\hline Nausea/vomiting & 7 & 3.4 \\
\hline Weight loss & 6 & 2.9 \\
\hline Dysphagia & 6 & 2.9 \\
\hline Chronic diarrhea & 11 & 5.3 \\
\hline Abdominal pain & 9 & 4.4 \\
\hline Anemia & 26 & 12.6 \\
\hline Gastrointestinal bleeding & 8 & 3.9 \\
\hline \multicolumn{3}{|l|}{ Endoscopic findings } \\
\hline LES relaxation & 82 & 39.8 \\
\hline Hiatal hernia & 16 & 7.8 \\
\hline Erythematous antral gastritis & 24 & 11.7 \\
\hline Erythematous pangastritis & 131 & 63.6 \\
\hline Erosive gastritis & 40 & 19.4 \\
\hline Gastric ulcer & 4 & 1.9 \\
\hline Duodenal ulcer & 4 & 1.9 \\
\hline
\end{tabular}

LES: Lower esophageal sphincter; UGIE: Upper gastrointestinal endoscopy. $\neq$ Use of nonsteroidal anti-inflammatory drugs, acetylsalicylic acid, other antiplatelet drugs.

indications, and endoscopic findings are presented in Table 2. Pathological abnormalities were seen in 76 patients $(36.9 \%)$. Most common pathological abnormality was increase in intraepithelial lymphocyte (IEL) count, detected in 33\% $(n=68)$ of patients. Second most frequent pathological finding was crypt hyperplasia, established in 54 cases (26.2\%). No microorganism was detected in study population. Histopathological assessment of duodenal biopsies is provided in Table 3.

Eight patients (3.9\%) were diagnosed as celiac disease according to endoscopic, serological, and histopathological findings (Table 4). Six of them
TABLE 3. Histopathological findings of study population

\begin{tabular}{lcc} 
& \multicolumn{2}{c}{ Total $(\mathrm{n}=206)$} \\
\cline { 2 - 3 } & $\mathrm{n}$ & $\%$ \\
\hline Pathological abnormality & 76 & 36.9 \\
Villous height and architecture & & \\
$\quad$ Normal & 187 & 90.8 \\
$\quad$ Broad & 11 & 5.3 \\
Blunted & 8 & 3.9 \\
Villous to crypt ratio (V:C) & & \\
$\quad$ 3:1 & 4 & 1.9 \\
4:1 & 37 & 18.0 \\
5:1 & 163 & 79.1 \\
Surface enterocytes & & \\
$\quad$ Normal & 186 & 90.3 \\
$\quad$ Flattened & 9 & 4.4 \\
$\quad$ Damaged & 11 & 5.3 \\
Presence of crypt hyperplasia & 54 & 26.2 \\
Intraepithelial lymphocyte increase & 68 & 33.0 \\
Gastric metaplasia in chronic duodenitis & 18 & 8.7 \\
Presence of microorganisms & 0 & 0 \\
& & \\
& & \\
& &
\end{tabular}

(75\%) were female. Mean age was $38.25 \pm 16.6$ years. Referral indications were epigastric pain in 3 cases, dyspepsia in 1 , diarrhea in 2 , diarrhea with abdominal pain in 1 , and anemia with vitamin B12 deficiency in 1 patient. $H$. pylori was present in 5 patients $(67.5 \%)$. Duodenitis was prominent finding of endoscopic examination in all patients with celiac disease. Histopathological findings were consistent with Marsh III classification in 6 patients (75\%). Duodenal biopsies of 2 patients (25\%) were classified as Marsh II.

After exclusion of cases with celiac disease, 198 patients were assessed for influence of $H_{\text {. }}$ pylori presence or drug use on development of duodenitis. Table 5 is a summary of histopathological findings with re-

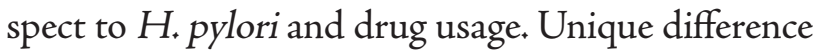
was presence of pathological abnormality between groups $(p=0.04)$. There was no difference between groups in subclassification of pathological abnormality (all $\mathrm{p}>0.05$ ). In subgroup analysis, pathological abnormality was more common among patients who 
TABLE 4. Demographic, clinical, and serological data, UGIE indications of patients with celiac disease, and histopathological findings according to Marsh classification

\begin{tabular}{|c|c|c|c|c|c|c|c|c|}
\hline & Age & Sex & Symptoms & $\begin{array}{l}\text { Endoscopic } \\
\text { findings }\end{array}$ & $\begin{array}{l}\text { H. pylori } \\
\text { status }\end{array}$ & $\begin{array}{l}\text { Drug } \\
\text { history }\end{array}$ & $\begin{array}{l}\text { Serological } \\
\text { positivity } \\
\text { marker }\end{array}$ & $\begin{array}{l}\text { Duodenal } \\
\text { pathological } \\
\text { findings }\end{array}$ \\
\hline 1 & 37 & M & Abdominal pain, diarrhea & $\begin{array}{l}\text { Hiatal hernia, antral } \\
\text { gastritis, duodenitis }\end{array}$ & + & + & AGA IgA, tTG IgA & Marsh IIIA \\
\hline 2 & 33 & $F$ & Anemia & Duodenitis & + & - & tTG IgA & Marsh IIIC \\
\hline 3 & 24 & $\mathrm{~F}$ & Diarrhea & Pangastritis, duodenitis & - & - & EMA IgA & Marsh II \\
\hline 4 & 66 & $\mathrm{~F}$ & Diarrhea & Pangastritis, duodenitis & + & + & EMA IgA & Marsh II \\
\hline 5 & 24 & $\mathrm{~F}$ & Epigastric pain & Antral gastritis, duodenitis & + & - & AGA IgA, tTG IgA & Marsh IIIA \\
\hline 6 & 24 & M & Epigastric pain, regurgitation & Pangastritis, duodenitis & - & + & EMA IgA, tTG IgA & Marsh IIIB \\
\hline 7 & 61 & $\mathrm{~F}$ & Epigastric pain & $\begin{array}{l}\text { Esophagitis, Gastric } \\
\text { ulcer, duodenitis }\end{array}$ & + & + & EMA IgA, tTG IgA & Marsh IIIB \\
\hline 8 & 37 & $\mathrm{~F}$ & Dyspepsia & LES relaxation, duodenitis & - & - & EMA IgG, tTG IgA & Marsh IIIC \\
\hline
\end{tabular}

AGA: Anti-gliadin antibody; EMA: Endomysial antibody; F: Female; LES: Lower esophageal sphincter; M: Male; tTG: Tissue transglutaminase antibody; UGIE: Upper gastrointestinal endoscopy.

TABLE 5. Duodenal histopathological findings regarding Helicobacter pylori infection and drug usage

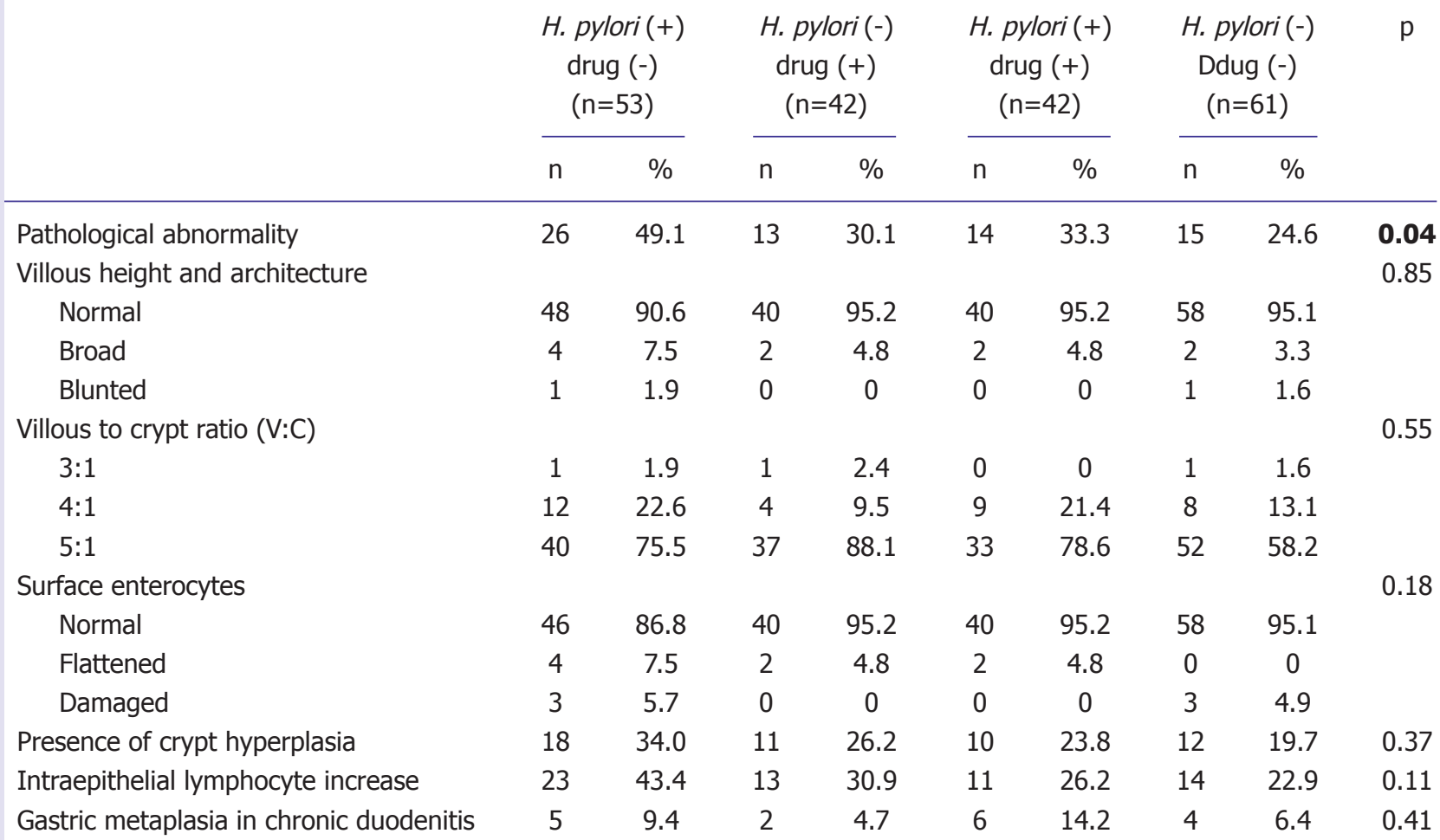


TABLE 6. Duodenal histopathological findings with respect to the presence of Helicobacter pylori after excluding patients with celiac disease

\begin{tabular}{|c|c|c|c|c|c|c|}
\hline & \multicolumn{2}{|c|}{$\begin{array}{l}\text { H. pylori }(+) \\
(\mathrm{n}=95)\end{array}$} & \multicolumn{2}{|c|}{$\begin{array}{l}\text { H. pylori }(-) \\
(\mathrm{n}=103)\end{array}$} & \multirow[t]{2}{*}{$\begin{array}{l}\text { Odds ratio } \\
(95 \% \mathrm{CI})\end{array}$} & \multirow[t]{2}{*}{$\mathrm{p}$} \\
\hline & $\mathrm{n}$ & $\%$ & $\mathrm{n}$ & $\%$ & & \\
\hline Pathological abnormality & 40 & 45 & 28 & 27.1 & $2.4(1.3-4.4)$ & 0.005 \\
\hline Villous height and architecture & & & & & & 0.61 \\
\hline Normal & 88 & 92.6 & 98 & 95.1 & & \\
\hline Broad & 6 & 6.3 & 4 & 3.9 & & \\
\hline Blunted & 1 & 1.0 & 1 & 1.0 & & \\
\hline Villous to crypt ratio $(\mathrm{V}: \mathrm{C})$ & & & & & & 0.13 \\
\hline $3: 1$ & 1 & 1.0 & 2 & 1.9 & & \\
\hline $4: 1$ & 21 & 22.1 & 12 & 11.6 & & \\
\hline $5: 1$ & 73 & 76.8 & 89 & 86.4 & & \\
\hline Presence of crypt hyperplasia & 28 & 29.5 & 23 & 22.3 & $1.5(0.8-2.8)$ & 0.25 \\
\hline Surface enterocytes & & & & & & 0.27 \\
\hline Normal & 86 & 90.5 & 98 & 95.1 & & \\
\hline Flattened & 6 & 6.3 & 2 & 1.9 & & \\
\hline Damaged & 3 & 3.2 & 3 & 2.9 & & \\
\hline Intraepithelial lymphocyte count & & & & & $1.6(0.9-2.9)$ & 0.14 \\
\hline Normal & 61 & 64.2 & 76 & 73.8 & & \\
\hline Increased & 34 & 35.8 & 27 & 26.2 & & \\
\hline Gastric metaplasia in chronic duodenitis & 11 & 10 & 6 & 5.8 & $2.1(0.8-5.9)$ & 0.15 \\
\hline Presence of microorganisms & 0 & 0 & 0 & 0 & & \\
\hline
\end{tabular}

CI: Confidence interval.

were infected with $H_{*}$ pylori and without drug use

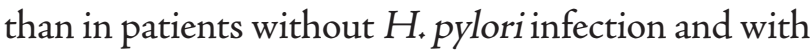
drug usage (49.1\% vs $24.6 \%$; OR, 2.9; $95 \%$ CI, $1.3-$ $6.5 ; \mathrm{p}=0.007)$. In the same manner, rate of IEL increase was higher in patients who were only infected

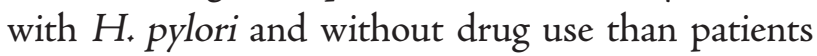

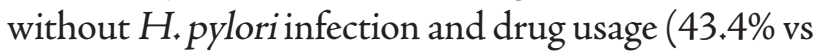
22.9\%; OR, 2.5; 95\% CI, 1.1-5.7; $\mathrm{p}=0.02$ ).

In total, H. pylori was found in $95(47.9 \%)$ cases. Histopathological duodenitis was more common among patients infected with $H_{*}$ pylori compared to $H$. pylori negative group (45\% vs $27.1 \%$; OR, 2.4; $95 \%$ CI, 1.3-4.4; $\mathrm{p}=0.005)$. Of those with histopathological duodenitis, $59 \%$ were $H$. pylori positive (Table 6). No difference was seen between groups according to IEL count, presence of crypt hyperplasia, villus atrophy, or gastric metaplasia (all p>0.05).
Total of 84 patients (42\%) were taking NSAID or ASA. Among those patients, 61 (73\%) were using proton pump inhibitor at time of UGIE and

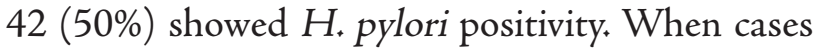
were evaluated according to drug usage, mean age of patients taking NSAID or ASA was higher than mean age of non-users $(51.5 \pm 16.5$ years vs $40.6 \pm 16.6$ years; $p=<0.001)$. There was no difference between those taking NSAID or ASA and nonusers according to presence of duodenitis, IEL count, presence of crypt hyperplasia, villus atrophy, or gastric metaplasia (all p>0.05).

\section{DISCUSSION}

Histological findings of the small intestine are well defined. Investigations of abnormalities in histo- 
logical findings have focused on celiac disease, in particular. Histopathological appearance of many diseases affecting duodenum is similar, so details in these findings are often not useful tools for diagnosis and management of diseases affecting the duodenal mucosa.

In this study, we investigated duodenal biopsy findings. However, we found that only $9.3 \%$ of patients who underwent endoscopic examination had duodenal biopsy sampling. Reason for sampling in most cases was endoscopic appearance of duodenal mucosa compatible with duodenitis. Other reasons were investigation of anemia, diarrhea, weight loss in setting of normal-appearing mucosa, and presence of intestinal lymphangectasia. Ratio of duodenal biopsy sampling has been reported in the literature to be between $10 \%$ and $12 \%$ among adult cases undergoing UGIE [7]. Our findings were consistent with these results.

Studies evaluating duodenal histopathological assessment generally focus on presence of celiac disease, and so most were conducted with patients who had normal-appearing mucosa. In a large series, it was found that duodenal biopsies were taken from normal-looking mucosa in $43 \%$ of patients who underwent UGIE due to anemia, diarrhea, or weight loss [8]. In nationwide study from the USA that was carried out on 103385 patients for 12 -month period, duodenal biopsy sampling rate was $27.2 \%$ [9]. An interesting result of that study was that endoscopic appearance of duodenitis, scalloping or erosion/ulcer, were detected in only $5.6 \%$ of whole patient population and in $8.5 \%$ of patients who had duodenal biopsy. Moreover, $79.5 \%$ of duodenal biopsies in study were evaluated as normal histopathological findings. In our study, duodenal biopsies were performed mostly due to endoscopic findings of duodenitis, and only $12.5 \%$ of patients who had duodenal biopsy had normal-appearing duodenal mucosa. Endoscopic/histopathological consistency was seen in $36.9 \%$ of patients who had duodenal biopsy.

Taking biopsy from patients who had endoscopic appearance of duodenitis is seen as more reliable compared with patients who had normal duodenal endoscopic findings. Diagnostic yield from biopsy sample obtained from normal-appearing mucosa is lower than result of current study. It should also be kept in mind that, although endoscopic/histopathological concordance is well established in esophageal and gastric lesions, agreement between duodenal endoscopic findings and histopathological findings is poor.

In clinical practice, main purpose of duodenal biopsy sampling is frequently to catch or to exclude silent or overt celiac disease. It is still diagnostic gold standard for celiac disease [10]. Eight patients (3.9\%) were diagnosed with celiac disease in current study. All of these patients had endoscopic appearance compatible with celiac disease. Our result is consistent with a long-period study from Canada [11]. In that study, celiac disease prevalence was $2.4 \%$ among 9665 patients for over 30-year period. In another large-scale study conducted by Carmack and collagenous et al,, celiac disease was detected in $1.2 \%$ of duodenal biopsy samples. Of patients who had clinical and endoscopic suspicion of celiac disease, $12 \%$ were diagnosed with the disease in histopathological assessment, and $64 \%$ of these patients had normal histopathological findings. [9]. In this study, celiac disease was diagnosed in $3.0 \%$ of those with diarrhea, weight loss, or anemia, and in $1.5 \%$ of patients with dyspepsia or gastroesophageal reflux disease. An interesting finding of our study was that referral indications for UGIE were gastrointestinal symptoms, such as epigastric pain and dyspepsia, in half of the patients diagnosed with celiac disease.

Based on results of the above studies and our findings, patients with anemia, weight loss, or diarrhea would all have low probability of having celiac disease at initial clinical assessment. Moreover, endoscopic appearance of duodenitis is not sufficient to make decision on celiac disease. Given limitations of biopsy, including interindividual variability in interpretation and challenges of appropriate sample handling, preferred approach should be to evaluate serological markers prior to endoscopic examination for GI symptoms or other malabsorptionrelated symptoms (diarrhea, weight loss, anemia). Thus, unnecessary biopsy can be avoided.

Current study demonstrated $H$. pylori positivity of $48 \%$ in study population, most of whom were 
diagnosed endoscopically as duodenitis. H. pylori prevalence has been reported to range from $71.3 \%$ to $82.5 \%$ in studies from Turkey $[12,13]$. Lower prevalence of $H$. pylori in current study population may have been due to high rate of drug usage and affect on gastric and duodenal mucosa.

It is well known that NSAIDs and ASA are important causes of gastroduodenal lesions, especially in $H_{\text {. pylori }}(-)$ patients $[14,15]$. Aside from NSAID-induced gastric mucosal damage, harmful effects of NSAIDs and ASA on intestinal mucosa are well established with widespread use of intestinal examination $[16,17]$. A study evaluating patients with obscure GI bleeding showed that ulcerative lesions were due to chronic NSAID use, and mostly located in the ileum. ASA and other antiplatelet drugs cause erosions in all parts of small intestine (jejunum and ileum) [18]. Data about effect of NSAIDs on duodenal mucosa are conflicting. In 1 study, NSAIDs were found to be responsible for only $13 \%$ of $H$. pylori (-) duodenal ulcers [15]. Lewis et al. demonstrated that although NSAID drug use was associated with endoscopic appearance of duodenitis, impact of NSAIDs on histological inflammation was minimal [2]. Alternatively, histological changes were prominent in $H_{*}$ pyloriinfected patients who had normal endoscopic appearance. This explains why histological findings did not differ between groups taking NSAID/ASA and nonusers in current study.

Mirbagheri et al. demonstrated that $H$. pylori infection had close association with histological duodenitis [3]. H. pylori presence was $67.3 \%$ in their study, and duodenitis was detected in $82.2 \%$

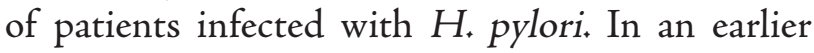
study, histological duodenitis was found to be in-

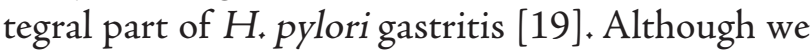

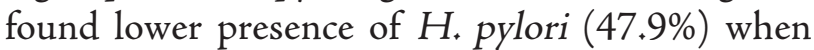
compared with mentioned studies, it is demonstrated in current study that $H_{\text {. pylori presence was }}$ major contributor to histopathological duodenitis, as $59 \%$ of those with histopathological duodenitis were infected with $H_{\text {. }}$ pylori.

Gastric metaplasia develops in response to increased duodenal acid load, and has been found with high frequency in $H$. pylori-infected patients, at prevalence of $55 \%$ in duodenal ulcer patients and about $25 \%$ in those with distal gastric ulcer [1, 20]. High acid load is key event causing development of gastric metaplasia. Gastric metaplasia is considered adaptive event in response to high acid exposure [19]. Genta et al. demonstrated that $H$. pylori gastritis was lower in patients with gastric metaplasia without inflammation $(6.3 \%)$ than in patients with normal duodenal histology (9.8\%) [21]. They concluded that high rate of $H$. pylori negativity among patients with gastric metaplasia without inflammation would open role of $H_{\text {. pylori }}$ in development of gastric metaplasia to discussion. Contrary to that study, we found that although it did not reach statistical significance, gastric metaplasia was more prevalent among patients who had positive test for $H_{\text {. }}$ pylori.

Most common pathogenic microorganism detected in duodenal biopsy is Giardia lamblia. In a study, Giardia lamblia was detected in $0.45 \%$ of 2000 patients undergoing UGIE [22]. Another study from Turkey reported that $2 \%$ of patients with iron deficiency anemia had Giardia lamblia detected in duodenal biopsies [23]. We found no microorganisms in duodenal biopsies of our unselected population. This might be due to small size of our study population.

Major limitation of this study is its retrospective nature. Although duodenal biopsies were revaluated, presence of H. pylori was determined according to the pathology reports and endoscopy reports. To standardize pathological assessment, samples were evaluated according to single standard system by one expert pathologist. Clinical and demographic data, including drug usage, were obtained from hospital records and public health insurance system records. Non-prescription drug usage, especially nonprescription NSAIDs, could not be determined due to retrospective nature of this study and use might be underestimated. In this study, although patho-

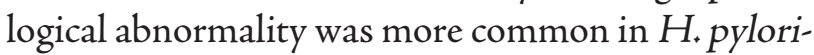

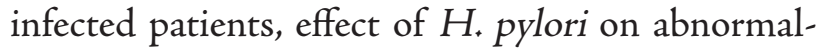
ity subgroups did not reach statistical significance in our population. However, further studies are needed to evaluate effects of $H_{\text {. pylori on duodenal }}$ mucosa in terms of histopathological abnormality 
subgroups. This study was a single center study conducted in eastern Turkey. Thus, our results cannot be accepted as having universal validity for Turkish population.

In conclusion, duodenal biopsy endoscopic/histopathological concordance is lower than of esophageal and gastric cases. Although most common purpose of duodenal biopsy is diagnosis of celiac disease, histopathological findings rarely direct specific diagnosis. Biopsy of duodenum has low diagnostic yield. $H$. pylori is main cause of duodenitis in regions where it is prevalent. Routine duodenal biopsy for endoscopic appearance of duodenitis in areas endemic for H. pylori is not most reasonable approach. Checking serological markers before UGIE is more accurate method to manage appearance of endoscopic duodenitis.

\section{Conflict of Interest: None declared.}

Financial Disclosure: The authors declared that this study has received no financial support.

Authorship contributions: Concept - A.S., G.C.; Design A.S., G.C.; Supervision - Y.B.; Materials - A.S., G.C., Y.B.; Data collection \&/or proseccing - A.S., Y.B.; Analysis and/or interpretation - G.C., M.C.; Literature search; A.S., T.C.; Writing - A.S., Critical review - G.C., M.C., T.C.

\section{REFERENCES}

1. Walker MM, Talley NJ. Clinical value of duodenal biopsiesbeyond the diagnosis of coeliac disease. Pathol Res Pract 2011;207:538-44.

2. Lewis S, Stableforth W, Awasthi R, Awasthi A, Pitts N, Ottaway $\mathrm{J}$, et al. An examination of the relationship between the endoscopic appearance of duodenitis and the histological findings in patients with epigastric pain. Int J Clin Exp Pathol 2012;5:581-7.

3. Mirbagheri SA, Khajavirad N, Rakhshani N, Ostovaneh MR, Hoseini SM, Hoseini V. Impact of Helicobacter pylori infection and microscopic duodenal histopathological changes on clinical symptoms of patients with functional dyspepsia. Dig Dis Sci 2012;57:967-72.

4. Kakar S, Nehra V, Murray JA, Dayharsh GA, Burgart LJ. Significance of intraepithelial lymphocytosis in small bowel biopsy samples with normal mucosal architecture. Am J Gastroenterol 2003;98:2027-33.

5. Serra S, Jani PA. An approach to duodenal biopsies. J Clin Pathol 2006;59:1133-50.

6. Marsh MN. Gluten, major histocompatibility complex, and the small intestine. A molecular and immunobiologic approach to the spectrum of gluten sensitivity ('celiac sprue'). Gastroenterology 1992;102:330-54.
7. Dubin SM, Kwong WT, Kalmaz D, Savides TJ. Low yield of routine duodenal biopsies for evaluation of abdominal pain. World J Gastroenterol. 2015;21:7495-9.

8. Lebwohl B, Tennyson CA, Holub JL, Lieberman DA, Neugut AI, Green PH. Sex and racial disparities in duodenal biopsy to evaluate for celiac disease. Gastrointest Endosc 2012;76:779-85.

9. Carmack SW, Genta RM. The diagnostic value of the duodenal biopsy: a clinico-pathologic analysis of 28,000 patients. Dig Liver Dis 2010;42:485-9.

10. Rubio-Tapia A, Hill ID, Kelly CP, Calderwood AH, Murray JA; American College of Gastroenterology. ACG clinical guidelines: diagnosis and management of celiac disease. Am J Gastroenterol 2013;108:656-76.

11. Freeman HJ. Detection of adult celiac disease with duodenal screening biopsies over a 30-year period. Can J Gastroenterol 2013;27:405-8.

12. Ozdil K, Sahin A, Kahraman R, Yuzbasioglu B, Demirdag H, Calhan T, et al. Current prevalence of intestinal metaplasia and Helicobacter pylori inf ection in dyspeptic adult patients from Turkey. Hepatogastroenterology 2010;57:1563-6.

13. Ozaydin N, Turkyilmaz SA, Cali S. Prevalence and risk factors of Helicobacter pylori in Turkey: a nationally-representative, crosssectional, screening with the ${ }^{13} \mathrm{C}$-Urea breath test. BMC Public Health $2013 ; 13: 1215$.

14. Gisbert JP, Calvet X. Review article: Helicobacter pylori-negative duodenal ulcer disease. Aliment Pharmacol Ther 2009;30:791815.

15. Chu KM, Kwok KF, Law S, Wong KH. Patients with Helicobacter pylori positive and negative duodenal ulcers have distinct clinical characteristics. World J Gastroenterol 2005;11:3518-22.

16. Graham DY, Opekun AR, Willingham FF, Qureshi WA. Visible small-intestinal mucosal injury in chronic NSAID users. Clin Gastroenterol Hepatol 2005;3:55-9.

17. Tsibouris P, Kalantzis C, Apostolopoulos P, Zalonis A, Isaacs PE, Hendrickse M, et al. Small bowel ulcerative lesions are common in elderly NSAIDs users with peptic ulcer bleeding. World J Gastrointest Endosc 2014;6:612-9.

18. Iwamoto J, Mizokami Y, Saito Y, Shimokobe K, Honda A, Ikegami T, et al. Small-bowel mucosal injuries in low-dose aspirin users with obscure gastrointestinal bleeding. World J Gastroenterol 2014;20:13133-8.

19. Caselli M, Gaudio M, Chiamenti CM, Trevisani L, Sartori S, Saragoni L, et al. Histologic findings and Helicobacter pylori in duodenal biopsies. J Clin Gastroenterol 1998;26:74-80.

20. Veijola L, Sankila A, Rautelin H, Kosunen TU, Sipponen P, Hyvärinen $\mathrm{H}$, et al. Clinical significance of widespread gastric metaplasia in the duodenal bulb. J Clin Gastroenterol 2006;40:510-4.

21. Genta RM, Kinsey RS, Singhal A, Suterwala S. Gastric foveolar metaplasia and gastric heterotopia in the duodenum: no evidence of an etiologic role for. Hum Pathol 2010;41:1593-600.

22. Chew TS, Hopper AD, Sanders DS. Is there a role for routine duodenal biopsy in diagnosing giardiasis in a European population? Scand J Gastroenterol 2008;43:1219-23.

23. Gonen C, Yilmaz N, Yalcin M, Simsek I, Gonen O. Diagnostic yield of routine duodenal biopsies in iron deficiency anaemia: a study from Western Anatolia. Eur J Gastroenterol Hepatol 2007;19:37-41. 